\title{
Regioselective Biocatalytic Transformations Employing Transaminases and Tyrosine Phenol Lyases
}

\author{
Lía Martínez-Montero ${ }^{1}$ Joerg H. Schrittwieser ${ }^{1} \cdot$ Wolfgang Kroutil $^{1}$
}

Published online: 6 October 2018

(c) The Author(s) 2018

\begin{abstract}
Regioselective reactions allow the differentiation between two or more chemically identical reactive centers within the same molecule. They are highly desirable transformations in organic synthesis, as they avoid additional chemical operations and sophisticated protection/deprotection strategies. In this context, enzymes, which present exquisite selectivity and reactivity, have been widely employed as catalysts in numerous regioselective transformations. This review focuses on two recently developed biocatalytic processes that present outstanding regioselectity: the transaminase-catalyzed asymmetric amination of di- and triketo compounds, and the stereoselective $\mathrm{C}-\mathrm{C}$ coupling between phenol derivatives, ammonia and pyruvate for the synthesis of tyrosine analogues, catalyzed by tyrosine phenol lyases. Additionally, elegant and straightforward cascades that have combined the aforementioned biotransformations with other enzymatic and/or chemocatalytic processes are compiled in this contribution. Overall, this review aims to provide a general view of the synthetic possibilities that two relatively recently described regio- and stereoselective biotransformations can provide.
\end{abstract}

Keywords Biocatalysis $\cdot$ Regioselectivity $\cdot$ Identical functional group differentiation · Transaminase $\cdot$ Tyrosine phenol lyase $\cdot$ Protecting-group-free

\section{Introduction}

Over the last 15 years, biocatalysis has emerged as a valuable tool in organic chemistry that provides straightforward and efficient alternatives to the traditional chemical and chemocatalytic approaches used in synthesis. Among the various advantages of the use of enzymes for synthetic purposes, the most important is probably their inherent selectivity [1]. When enzymes catalyze the transformation of a substrate, they can distinguish between different stereoisomers or different orientations of prochiral/meso compounds (stereoselectivity), between different functional groups (chemoselectivity), or between functional groups that are chemically identical but situated in different positions within the same molecule (regioselectivity) [2].

Regioselective transformations are highly desirable in organic synthesis as they avoid additional reaction steps and

Wolfgang Kroutil

Wolfgang.Kroutil@uni-graz.at

1 Institute of Chemistry, Organic and Bioorganic Chemistry, University of Graz, NAWI Graz, BioTechMed Graz,

Heinrichstrasse 28, 8010 Graz, Austria sophisticated protection/deprotection strategies [3, 4], thus resulting in simpler, higher-yielding and more cost-effective synthesis routes. Consequently, protecting-group-free strategies are considered superior to traditional protectionbased routes and have received well-deserved recognition $[5,6]$. In the field of biocatalysis, regioselective reactions have been described for numerous enzyme classes, whereby hydrolytic enzymes have been studied in most detail $[7,8]$. For instance, in carbohydrate chemistry, lipases can catalyze the selective acylation of a single primary [9] or secondary alcohol [10] in the presence of several other primary or secondary hydroxyl groups, respectively. Among other selective transformations, lipases also catalyze the monoamidation of glutamic acid diesters [11], the monodeacetylation of di- or triacetoxyacetophenones by transesterification [12], and the monoacetylation of dihydroxybenzene derivatives with vinyl acetate [13]. Likewise, dinitriles have been hydrolyzed to the corresponding monocarboxylic acids by nitrilases [14] or to monoamides by nitrile hydratases [15] with moderate to excellent regioselectivity. Epoxide hydrolases showing opposite regioselectivity on the $(S)$ - and $(R)$-enantiomer of the same substrate have been used for the enantioconvergent hydrolysis of racemic mixtures of oxiranes [16-28] into 
vicinal diols. Methyl transferases perform highly regioselective methylations in vivo and have also been successfully employed in biocatalysis for regioselective alkyl transfer, in some cases using non-natural derivatives of the $S$-adenosyl methionine (SAM) cofactor as alkyl donors [29-33]. Oxidoreductases are also capable of differentiating between identical functional groups: Alcohol dehydrogenases have been found to reduce one carbonyl group of diketo compounds with very high regio- and enantioselectivity [34, 35], and both native and evolved P450 monooxygenases have successfully been applied in the regio- and stereoselective hydroxylation of arenes, linear alkanes, terpenes, and steroids [36-45]. Also worth mentioning is the oxidative monocleavage of dialkenes at the expense of molecular oxygen that has been achieved using an enzyme preparation from the fungus Trametes hirsuta [46].

Among the different regioselective enzymatic reactions existing in literature, in this contribution we will focus on two biotransformations that have gained particular relevance in the last few years. These are the monoamination of multiketo compounds catalyzed by transaminases, and the paraselective $\mathrm{C}-\mathrm{C}$ bond formation reaction mediated by tyrosine phenol lyases on para-unsubstituted phenols. In addition, examples of cascades that have employed either of these biotransformations in combination with further biocatalytic processes for the regio- and stereoselective synthesis of nitrogen heterocycles and tyrosine derivatives will be discussed in this review.

\section{Regioselective Transformations Catalyzed by Transaminases}

Optically pure amines are valuable building blocks in the synthesis of pharmaceuticals and agrochemicals. In addition, versatile applications as resolving agents, chiral auxiliaries and organocatalytic reagents have been reported for this compound class [47]. Therefore, synthetic organic chemists have historically devoted great effort to the development of efficient and versatile strategies for the stereoselective synthesis of chiral amines. These efforts have also led to the development of several biocatalytic methods for chiral amine synthesis, which rely on enzymes such as lipases, amine oxidases, imine reductases, and transaminases, among others [48-51]. Transaminases (TAs, EC 2.6.1.X) are pyridoxal 5'-phosphate (PLP)-dependent enzymes that mediate the stereoselective transfer of an amino group from an amine donor to a carbonyl acceptor. Depending on the stereopreference of the selected enzyme, $(S)$ - or $(R)$-amines can be accessed in high optical purity starting from the prochiral ketones [52-56]. Taking advantage of their potential, these biocatalysts have been implemented in pharmaceutical synthesis during the last decade. An outstanding example is the
TA-catalyzed stereoselective amination that has replaced a rhodium(I)-mediated asymmetric enamine hydrogenation as the key step in the manufacture of the antidiabetic drug Sitagliptin [57].

Focusing on the scope of this contribution, TAs have been successfully applied to regioselective transformations. In particular, the asymmetric monoamination of di- and triketones has been achieved. Most wild-type TAs present a high selectivity for the sterically less demanding ketone moiety, in particular methyl ketones, while carbonyl groups with more bulky substituents remain untouched. This selectivity was exploited for the regio- and stereoselective monoamination of diketones without the use of protecting groups [58]. 1,5-Diketo compounds were exclusively converted into one out of the two possible regioisomeric aminoketone intermediates. These species spontaneously cyclized, yielding the corresponding $\Delta^{1}$-piperideines in optically pure form (Scheme 1). By choosing TAs with suitable stereopreference, both enantiomers of the piperideines could be accessed in up to $>99 \%$ conversion and $e e$.

Diastereoselective reduction of the cyclic imines thus formed gave access to the corresponding 2,6-disubstituted piperidines. For instance, the two enantiomers of the alkaloids dihydropinidine [59] and isosolenopsin [60] were synthesized in three steps from the commercially available 6-methyl-3,4-dihydropyran-2-one with overall yields of $61-72 \%$ over three steps (Scheme 2a). Grignard reactions gave access to the corresponding 1,5-diketone compounds, which were regio- and stereoselectively transformed into the $\Delta^{1}$-piperideines through transaminase-catalyzed reactions. The cyclic imines were readily reduced by hydrogenation with palladium on charcoal $(\mathrm{Pd} / \mathrm{C})$ as catalyst, affording the cis-disubstituted piperidines with excellent diastereoselectivity (>98\% de). In a similar fashion, both enantiomers of the alkaloid epi-dihydropinidine (Scheme $2 b$ ) were accessed in high yield (up to $91 \%$ over two steps) and moderate diastereoselectivity when the enantiopure imine intermediate was treated with $\mathrm{LiAlH}_{4}$ in the presence of $\mathrm{Et}_{3} \mathrm{Al}$ [59]. This reduction reaction, in contrast to the $\mathrm{Pd} / \mathrm{C}$-catalyzed hydrogenation, affords predominantly the anti-diastereoisomers.

An extension of this concept was recently used in the chemo-enzymatic asymmetric synthesis of both enantiomers of the ant venom alkaloid xenovenine [61]. A key step in this process is the biocatalytic amination of a triketone intermediate, which was prepared in two steps starting from commercially available 2-( $n$-heptyl)furan (Scheme 3$)$. Two enantiocomplementary TAs from Arthrobacter sp. mediated the regio- and stereoselective amination of the least sterically demanding carbonyl group, followed by the spontaneous cyclization of the resulting intermediate. The fivemembered cyclic amine obtained was aromatized to the corresponding pyrrolizidine by subjecting the crude product of the biotransformation to a $0.1 \% \mathrm{v} / \mathrm{v}$ solution of acetic acid 


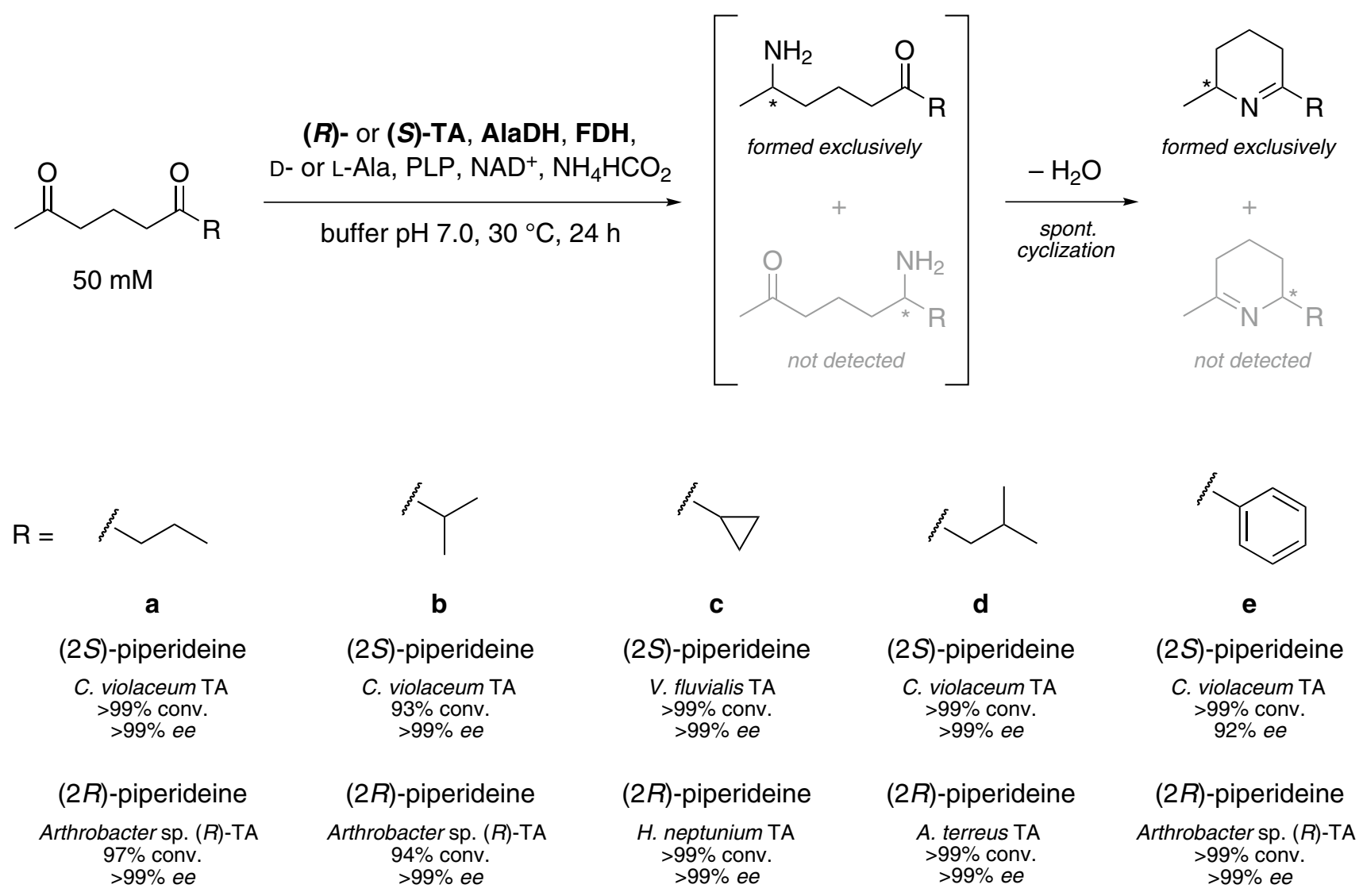

Scheme 1 Regioselective amination of various 1,5-diketones. AlaDH alanine dehydrogenase, $F D H$ formate dehydrogenase

in methanol. Finally, the hydrogenation of this compound catalyzed by $\mathrm{Pd} / \mathrm{C}$ in the presence of camphorsulphonic acid (CSA) led to the desired $(5 Z, 8 E)$-diastereoisomer, independently of the substrate enantiomer. Thus, the naturally occurring (+)-enantiomer was obtained in $30 \%$ isolated yield over the three steps by treating the triketone with the $(R)$-TA from Arthrobacter sp., whereas the (S)-TA from Arthrobacter sp. led to the formation of (-)-xenovenine in $48 \%$ yield. Both antipodes were isolated in enantio- and diastereomerically pure form.

Taking further advantage of this methodology, an elegant multienzymatic approach combining TAs and mononoamine oxidases (MAOs) has been described for the asymmetric synthesis of 2,5-disubstituted pyrrolidines [62, 63]. The authors employed two commercially available transaminases with opposite stereopreference, ATA-113 and ATA-117, for the regio- and stereoselective synthesis of $(S)$ - and $(R)-\Delta^{1}$ pyrrolines, respectively. In this case, hydrogenation of the cyclic imines over $\mathrm{Pd} / \mathrm{C}$ proceeded with poor diastereoselectivity and was hence not a suitable method for obtaining the corresponding disubstituted pyrrolidines as pure stereoisomers. Instead, the authors implemented a 'cyclic deracemisation' system using monoamine oxidase and ammonia-borane to obtain the desired chiral pyrrolidines in excellent optical purity (Scheme 4). The non-selective reducing agent $\mathrm{NH}_{3} \cdot \mathrm{BH}_{3}$ reduces the cyclic imine to a mixture of diasteroisomers of the desired amine. Engineered variants of monoamine oxidase from Aspergillus niger (MAO-N) catalyze the selective oxidation of the (5S)-diastereomer back to the imine. Successive rounds of reduction and oxidation, which take place concurrently in the same reaction vessel, lead to accumulation of the $(5 R)$-configured pyrrolidine in $>99 \% d e$. Due to the complementary regioselectivity displayed by the TAs and the MAO-N variants, the stereochemistry of $\mathrm{C} 2$ (established by the TA) was not affected by MAO-N. Consequently, the cascade proceeded with excellent enantio- and diasteroselectivity (up to $>99 \%$ ee and $>99 \%$ de) for almost all cases studied.

Due to the fact that this contribution focuses only on regioselective processes, TA-catalyzed conversion of ketones in the presence of ester groups within the same molecule [64-66], or the differentiation between aldehyde and ketone groups are out of the scope of this review [67, 68]. 
(a)
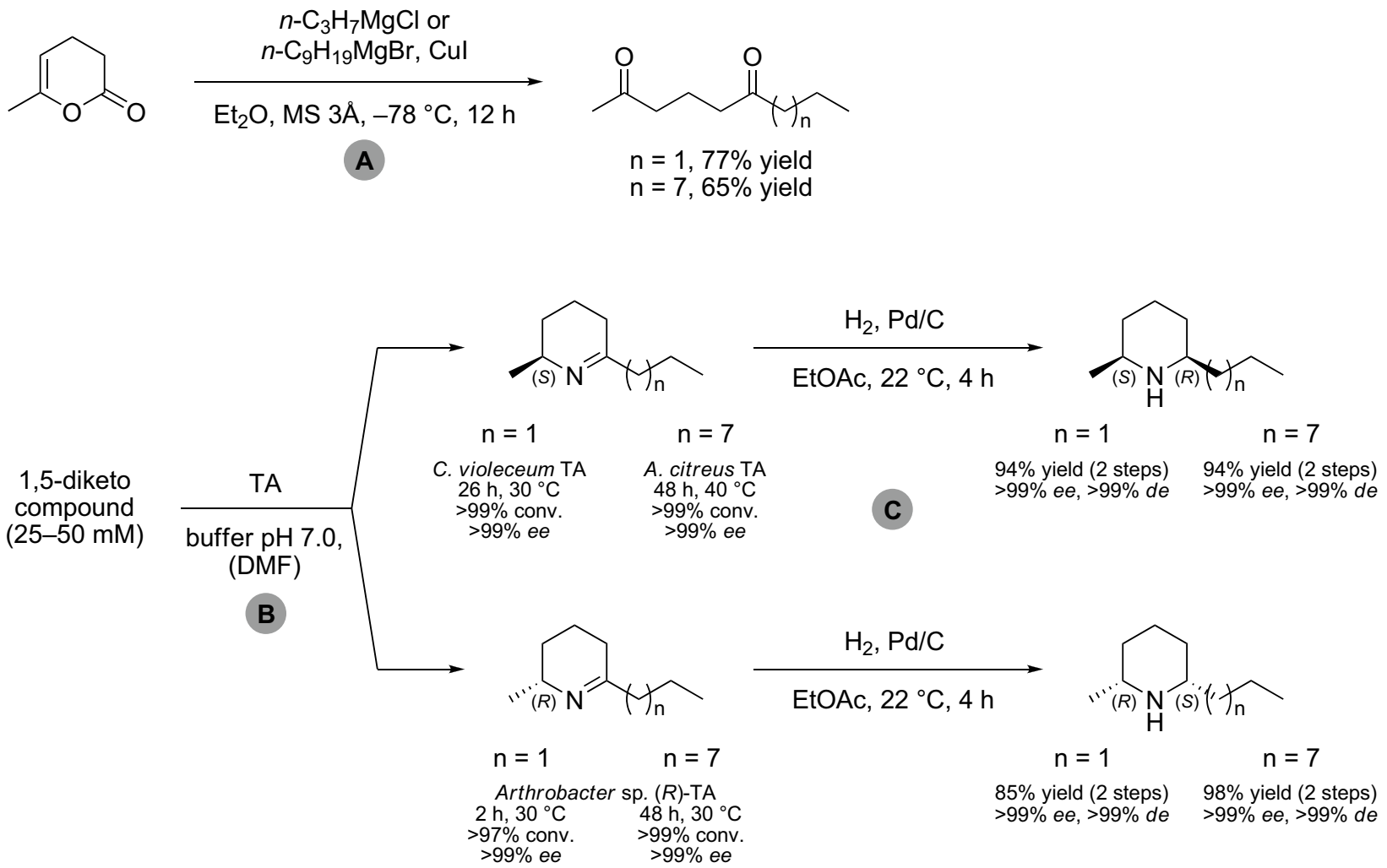

(b)

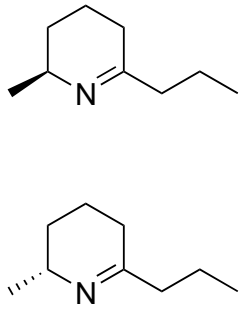

$$
\begin{aligned}
& \frac{\mathrm{Et}_{3} \mathrm{Al} \text { (10 eq.), } \mathrm{LiAlH}_{4} \text { (5 eq.) }}{\mathrm{THF},-78^{\circ} \mathrm{C}, 2 \mathrm{~h}} \\
& \underset{\mathrm{Et}_{3} \mathrm{Al}\left(10 \text { eq.), } \mathrm{LiAlH}_{4}\right. \text { (5 eq.) }}{\mathrm{THF},-78^{\circ} \mathrm{C}, 2 \mathrm{~h}}
\end{aligned}
$$

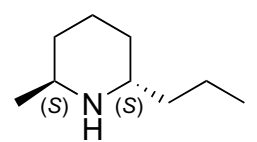

$85 \%$ yield (two steps)

$>99 \%$ ee, $68 \%$ de

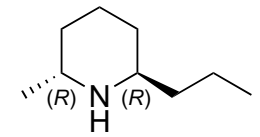
$>99 \%$ ee, $64 \%$ de
$91 \%$ yield (two steps)
Scheme 2 a Total synthesis of the two enantiomers of dihydropinidine $(n=1)$ and isosolenopsin $(n=7)$. The chemoenzymatic approach combines a Grignard reaction [A], a TA-catalyzed regioselective monoamination $[\mathrm{B}]$, and a diastereoselective syn-hydrogenation cata- lyzed by $\mathrm{Pd} / \mathrm{C}[\mathrm{C}]$. b Synthesis of $(2 S, 6 S)$ - and $(2 R, 6 R)$-epi-dihydropinidine. Imine intermediates were synthesized as shown in $\mathbf{a}$, and then reduced by $\mathrm{LiAlH}_{4}$ in the presence of $\mathrm{Et}_{3} \mathrm{Al}$ affording the antidiastereoisomers

\section{Regioselective Transformations Catalyzed by Tyrosine Phenol Lyases}

The formation of carbon-carbon $(\mathrm{C}-\mathrm{C})$ bonds is the key reaction in organic synthesis that builds the carbon framework of every organic molecule by connecting smaller and simpler substructures. The development and identification of new biocatalysts able to mediate $\mathrm{C}-\mathrm{C}$ couplings with high control of chemo-, regio- and stereoselectivity has undoubtedly expanded the chemist's toolbox for the synthesis of multifunctional products [69]. For instance, the chemical synthesis of tyrosine derivatives, which are valuable building blocks in the synthesis of several anti-cancer therapeutics [70, 71], comprises several laborious and time-consuming steps. In contrast, PLP-dependent tyrosine phenol lyases (TPLs, EC 4.1.99.2) can catalyze the regio- and stereoselective reversible formation of tyrosine from pyruvate, phenols and ammonia in a single and "green" reaction [72-74]. TPLs are not limited to phenol as substrate, however: For instance, the TPL from Erwinia herbicola has been used to convert catechol into L-dihydroxyphenylalanine (L-DOPA) [75, 76], and this reaction 
Scheme 3 Total synthesis of the two enantiomers of ( $5 Z$, $8 E$ )-xenovenine. The chemoenzymatic approach combines a retro-Paal-Knorr reaction [A], a TA-catalyzed regioselective monoamination $[\mathrm{B}]$, an aromatization reaction $[\mathrm{C}]$, and a diastereoselective hydrogenation catalyzed by $\mathrm{Pd} / \mathrm{C}$ in the presence of CSA [D]. $\mathrm{R}=n$ $\mathrm{C}_{7} \mathrm{H}_{15} \mathrm{CSA}=$ camphorsulfonic acid

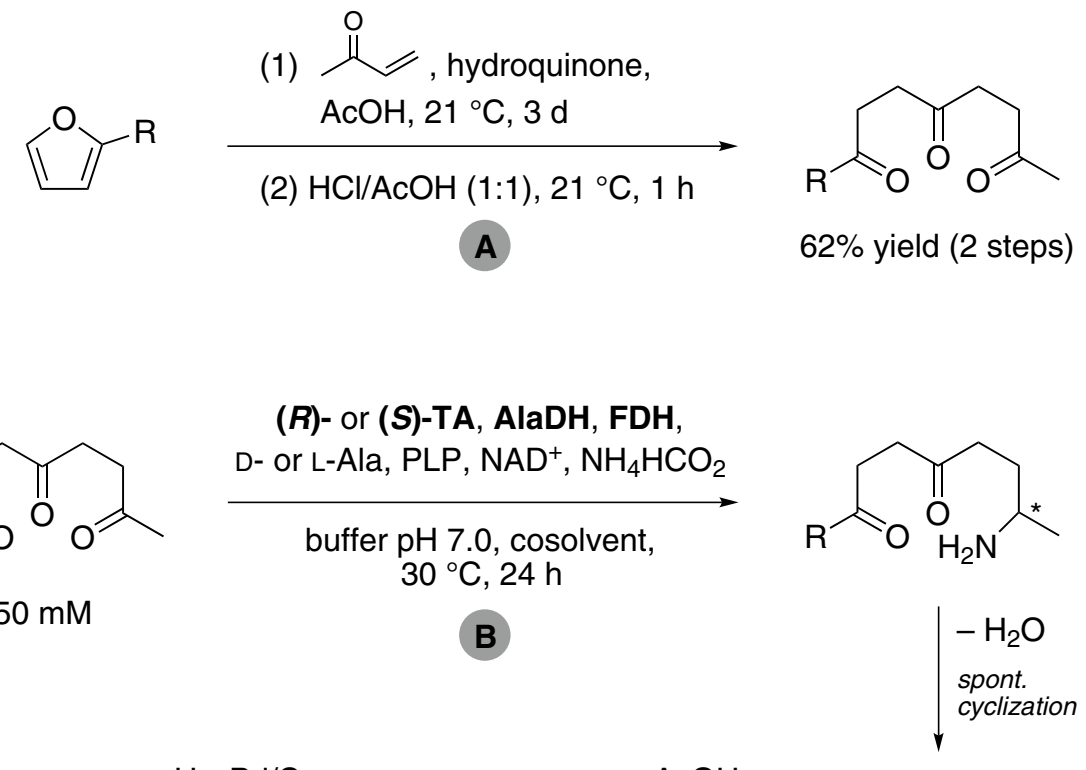

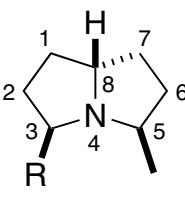

(5Z,8E) up to $87 \%$

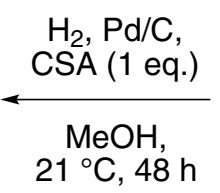<smiles>[R]c1ccc2n1[C@H](C)CC2</smiles>

$\mathrm{AcOH}$

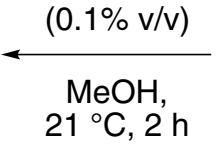

D $>99 \%$ conv.
C
(S): $91 \%$ conv., $>99 \%$ ee (R): $79 \%$ conv., $>99 \%$ ee<smiles>[R]c1ccc(C(=O)CCC(C)=O)cc1</smiles>

5-50 mM
$\mathrm{R}=\mathrm{H},>99 \%$ conv., $>99 \%$ de Me, $>99 \%$ conv., $>99 \%$ de $\mathrm{F},>99 \%$ conv., $>99 \%$ de OMe, $>99 \%$ conv., $>99 \%$ de
ATA-113, GDH,<smiles>C[C@@H]1CCC([Al])=N1</smiles>
$30{ }^{\circ} \mathrm{C}, 24 \mathrm{~h}$

A

$\mathrm{NH}_{3} \cdot \mathrm{BH}_{3}$

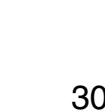
$30{ }^{\circ} \mathrm{C}, 24 \mathrm{~h}$

non-stereoselective reduction

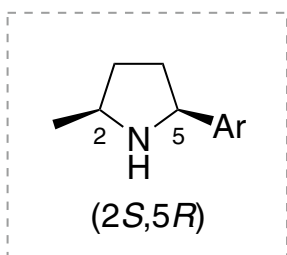

Accumulates
B

MAO-N D5 $30{ }^{\circ} \mathrm{C}, 24 \mathrm{~h}$ enantioselective oxidation
Scheme 4 ATA-113/MAO-N one-pot sequential process for the synthesis of $(2 S, 5 R)$-disubstituted pyrrolidines. [A] First step, regio- and stereoselective amination of 1,4-diketones catalyzed by the $(S)$-selec- tive ATA-113. [B] Second step, the MAO-N/ $\mathrm{NH}_{3} \cdot \mathrm{BH}_{3}$ system mediates the diastereoselective conversion of the $(S)$-pyrrolines into the corresponding $(2 S, 5 R)$-pyrrolidines. $G D H$ glucose dehydrogenase has very recently been applied to a bacterial system with an expanded genetic code that can biosynthesize DOPA and employ it for protein synthesis [77]. An engineered variant of TPL from Citrobacter freundii (M379V) has been shown to accept a range of 2 -substituted phenols as substrates, hence giving access to non-natural, monosubstituted L-tyrosine derivatives in moderate to excellent conversions (52-99\%) and excellent optical purity (ee $>99 \%$; Scheme 5). In all cases the C-C coupling occurred with excellent regioselectivity; therefore, only 
<smiles>[R]c1ccccc1O</smiles>

$23 \mathrm{mM}$<smiles>CC(=O)C(=O)O</smiles>

$46 \mathrm{mM}$
TPL from C. freundii M379V

KPi buffer $\mathrm{pH} 8$, PLP $30{ }^{\circ} \mathrm{C}, 24 \mathrm{~h}$

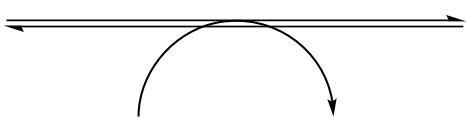

$\mathrm{H}_{2} \mathrm{O}$<smiles>[R]c1cc(C[C@@H](N)C(=O)O)ccc1O</smiles>

$\begin{aligned} \mathrm{R}= & \mathrm{CH}_{3},>99 \% \text { conv. } \\ & \mathrm{OMe}, 52 \% \text { conv. } \\ & \mathrm{F}, 89 \% \text { conv. } \\ & \text { Cl, } 58 \% \text { conv. }\end{aligned}$

Scheme 5 Single-step biocatalytic synthesis of monosubstituted L-tyrosine derivatives catalyzed by the single mutant M379V of TPL from Citrobacter freundii

the product bearing the substituent in position $3^{\prime}$ of tyrosine was detected [78].

Moreover, different enzyme engineering approaches have taken advantage of the activity shown by TPLs to successfully incorporate unnatural amino acids (UAAs) into recombinant proteins. While traditional mutagenesis is limited to the 'chemical space' of the 20 proteinogenic amino acids, the introduction of non-natural residues gives access to novel side-chain functionalities that can lead to more robust enzymes with enhanced catalytic properties [79]. For instance, a double variant of the TPL from Citrobacter freundii (M288S/F448C) has been used to catalyze the formation of the metal-chelating UAA 2-amino-3-(8hydroxyquinolin-5-yl)propanoic acid (HqAla, Scheme 6) from 8-hydroxyquinoline, ammonium chloride and pyruvate in high yield. After purification, HqAla was site-specifically incorporated into green fluorescent proteins, enabling them to sense $\mathrm{Cu}^{2+}$ ions, which opens the door for biosensing applications [80]. In addition, examples of improved enzymatic activity and modified selectivity resulting from the incorporation of UAAs were also reported by the same authors. In one study, a single variant of the Symbiobacterium sp. TPL (M379V) was used to access 3-methoxytyrosine (OMeY, Scheme 6) from 2-methoxyphenol. The tyrosine analog was selectively incorporated at a defined site in myoglobin, increasing the oxygen reduction activity of the protein and changing the predominant reaction product from $\mathrm{H}_{2} \mathrm{O}_{2}$ to water [81]. Likewise, the genetic incorporation of 3-methylthiotyrosine (SMeY, Scheme 6), also synthesized by a TPL-catalyzed coupling, into myoglobin provided a protein fourfold more active than the original enzyme towards the reduction of hydroxylamine to ammonia [82]. Both modifications mimic the active-site environment of other heme enzymes, namely cytochrome c oxidase $(\mathrm{OMeY})$ and cyctochrome $\mathrm{c}$ nitrite reductase $(\mathrm{SMeY})$. The preparation of various fluorotyrosines by TPL-catalysed $\mathrm{C}-\mathrm{C}$ coupling as well as the incorporation of these UAAs into peptides and proteins has also been reported [83, 84].

The excellent performance shown by TPLs for the regio- and stereoselective preparation of L-tyrosine derivatives has enabled the coupling of this reaction to other biocatalytic processes, resulting in several elegant multienzymatic cascades. For instance, the combined use of a P450 monoxygenase with the TPL variant M379V from Citrobacter freundii gave access to tyrosine analogs from substituted benzenes, pyruvate and ammonia in a onepot two-step cascade (Scheme 7a) [85]. In the first step, monosubstituted arenes were regioselectively hydroxylated in the ortho-position by the monooxygenase P450 $\mathrm{BM} 3$ at the expense of oxygen and NADPH, yielding the<smiles>N[C@@H](Cc1ccc(O)c2ncccc12)C(=O)O</smiles>

HqAla

C. freundii TPL M288S/F448C<smiles>COc1cc(C[C@H](N)C(=O)O)ccc1O</smiles>

OMeY

Symbiobacterium sp. TPL M379V<smiles>CSc1cc(C[C@H](N)C(=O)O)ccc1O</smiles>

SMeY

C. freundii TPL F36L<smiles>N[C@@H](Cc1cc(F)c(O)c(F)c1F)C(=O)O</smiles>

\section{$2,3,5-F_{3} Y$}

C. freundii TPL wild type

Scheme 6 Examples of unnatural amino acids produced by TPL-catalyzed C-C coupling that have been incorporated into proteins. The source organism and any amino acid variations of the used TPL are specified below the structures and their abbreviations 
(a)

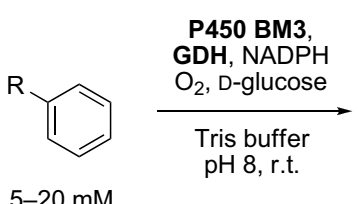

(b)<smiles>O=C(O)C(=O)[O+]c1ccc(O)cc1</smiles>

$23 \mathrm{mM}$<smiles>[R]c1ccccc1O</smiles>

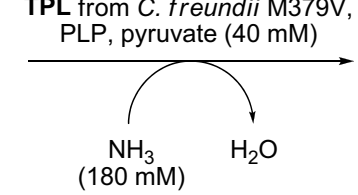<smiles>[R]c1cc(C[C@H](N)C(=O)O)ccc1O</smiles>

total reaction time: $6 \mathrm{~h}$

$\mathrm{R}=\mathrm{H}: 18 \%$ conv., $80 \%$ sel. $\mathrm{CH}_{3}: 87 \%$ conv., $30 \%$ sel. $\mathrm{OCH}_{3}: 82 \%$ conv., $72 \%$ sel. : $34 \%$ conv., $41 \%$ sel. Bl: $72 \%$ conv., $33 \%$ sel. (c)

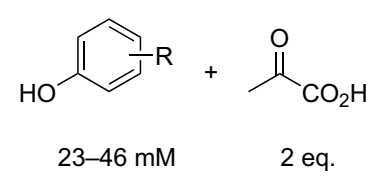

(d)

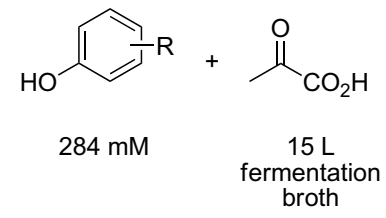

TPL from C. koseri, PLP, Triton X-100 $(10 \% \mathrm{v} / \mathrm{v})$, NaOÁc buffer $\mathrm{pH} 7,37^{\circ} \mathrm{C}, 6 \mathrm{~h}$

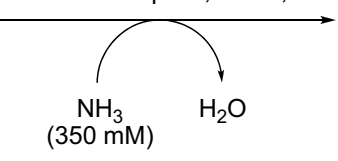

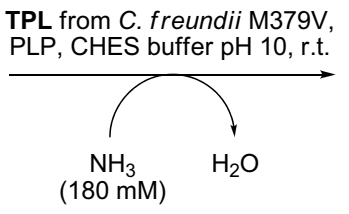

$\wedge$
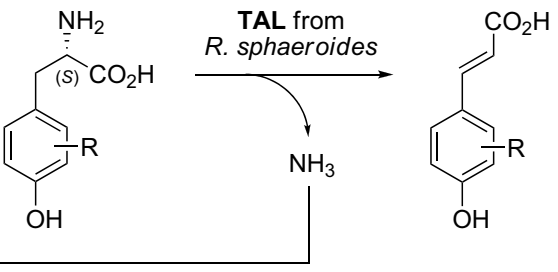

total reaction time: $24 \mathrm{~h}$

$\mathrm{R}=2-\mathrm{F},>95 \%$ conv.

$2-\mathrm{Cl},>95 \%$ conv.

2-Br, $>$-Me, $71 \%$ conv.

$3-\mathrm{M},>95 \%$ conv.

3-Cl, $69 \%$ conv.

2,3-diF, $>95 \%$ conv. 
corresponding phenols. These compounds were excellent substrates for the subsequent TPL-catalyzed process, and the desired amino acids were obtained in moderate to good conversion (up to $72 \%$ ) and chemoselectivity (up to $80 \%$ ). In some cases, a lower selectivity was observed as a result of an undesired P450-mediated overoxidation of the monosubstituted phenol intermediates.

More recently, the regioselective transformation catalyzed by TPL was successfully combined with a tyrosine ammonia lyase (TAL) from Rhodobacter sphaeroides, which mediated the ammonia elimination that gave access to $p$-coumaric acid derivatives from phenols. This biocatalytic process constituted the first direct para-selective alkenylation of these derivatives without the presence of an auxiliary group in para-position. Only pyruvate was used as stoichiometric reagent, as the ammonia that is consumed in the TPL-catalyzed coupling was internally regenerated in the elimination step mediated by the TAL, thus making water the sole coproduct [86]. Seven phenols (including halogenated derivatives) were thus transformed into the $\alpha, \beta$-unsaturated carboxylic acids with high to excellent conversions and perfect selectivity towards the $E$-isomer (Scheme $7 \mathrm{~b}$ ). The addition of a ferulic acid decarboxylase (FAD) to the bienzymatic process just described resulted in the formation of para-vinylphenols via decarboxylation of the corresponding $p$-coumaric acid derivatives (Scheme 7c). The FAD-catalyzed decarboxylation is an irreversible transformation that drives the equilibrium towards product formation, and consequently 2-, $3-$, and 2,3-substituted phenols were transformed into the para-vinylated products in excellent conversion (>99\%) for all the cases studied [87]. To highlight the importance of this contribution, it must be mentioned that, while vinyl arenes are important building blocks in organic chemistry, their synthesis from unprotected phenols is not straightforward. The chemical reaction with $\mathrm{SnCl}_{4} \cdot \mathrm{Bu}_{3} \mathrm{~N}$ leads to ortho functionalization [88], whereas the synthesis of para-vinylphenols involves transition-metal-catalyzed couplings in which the presence of auxiliary groups at the para-position is strictly necessary $[89,90]$.

In another bienzymatic approach, L-tyrosine formed by a TPL reaction was used as substrate for immobilized cells containing a heterologously expressed tyrosine decarboxylase (TDC). The latter mediated the decarboxylation of L-tyrosine, yielding tyramine [2-( $p$-hydroxyphenyl)ethylamine], a bioactive metabolite and valuable intermediate in the synthesis of pharmaceutical drugs [91]. The authors were able to scale up the two-step enzymatic process converting $15 \mathrm{~L}$ of pyruvate fermentation broth into the L-tyrosine intermediate in $94 \%$ isolated yield. The decarboxylation reaction provided the desired tyramine in $91 \%$ yield, thus reaching $86 \%$ overall yield after the two biocatalytic reactions (Scheme 7d).
Likewise, the TPL-catalyzed regio- and enantioselective tyrosine formation allowed the preparation of enantiopure $(R)$ - and $(S)$-p-hydroxyphenyl lactic acids when it was combined with two additional biocatalytic reactions that employed an L-amino acid deaminase (L-ADD) and an enantioselective hydroxyacid dehydrogenase, respectively [92]. This elegant three-step cascade was performed in one pot and subdivided into two different modules that were run sequentially. The first module comprised the L-tyrosine formation catalyzed by the TPL from Citrobacter freundii M379V, whereas the second module consisted of two biocatalytic transformations: the oxidative deamination mediated by the L-ADD from Proteus myxofaciens and the reduction of the resulting 2-keto acid derivatives using as catalysts the two stereocomplementary 2-hydroxyisocaproate dehydrogenases from Lactobacillus paracasei (L-HicDH) and Lactobacillus confusus (D-HicDH) (Scheme 7e). The TPL-L-ADD-HicDH cascade led to the transformation of $p$-unsubstituted phenols to both enantiomers of the corresponding $p$-hydroxyphenyl lactic acids in excellent conversion (92\% to $>99 \%$ ), high isolated yield $(58-85 \%)$ and excellent optical purity ( $96 \%$ to $>97 \%$ ) for all the cases studied.

\section{Conclusion and Outlook}

Enzyme catalysis has become a well-established discipline that provides valuable and efficient tools for the synthesis of pharmaceuticals and other bioactive compounds with excellent chemo-, regio- and stereoselectivity. This contribution focuses on two regioselective processes that, by definition, allow the differentiation between two or more chemically identical functional groups at different positions of a substrate molecule. Thus, several examples of asymmetric monoamination of di- and triketones catalyzed by transaminases have been discussed in detail. Likewise, a compilation of strategies that have taken advantage of the ability presented by tyrosine phenol lyases to distinguish between different sites of phenols, leading to the synthesis of L-tyrosine analogues, have also been described in this review. Both these regioselective processes have attained well-deserved recognition in recent years as a consequence of having shortened sophisticated and time-consuming synthesis routes for the preparation of drugs and important building blocks, thus resulting in protecting-group-free strategies with considerably higher yield and overall efficiency than traditional approaches.

Overall, transaminases and tyrosine phenol lyases catalyze highly selective and versatile transformations with a large potential for synthetic application, especially when combined with other enzymatic or chemocatalytic reactions. They thus represent a valuable extension of the 
organic chemist's toolbox for the preparation of chiral target molecules.

Acknowledgements Open access funding provided by University of Graz. The authors gratefully acknowledge BIOMIN Holding GmbH (Tulln, Austria) for financial support to Dr. Lía Martínez-Montero.

Open Access This article is distributed under the terms of the Creative Commons Attribution 4.0 International License (http://creativeco mmons.org/licenses/by/4.0/), which permits unrestricted use, distribution, and reproduction in any medium, provided you give appropriate credit to the original author(s) and the source, provide a link to the Creative Commons license, and indicate if changes were made.

\section{References}

1. García-Urdiales E, Lavandera I, Gotor V (2012) In: Drauz K, Gröger H, May O (eds) Enzyme catalysis in organic synthesis, 3rd edn. Wiley-VCH, Weinheim, pp 43-63

2. Faber K (2018) Biotransformations in organic chemistry, 7 th edn. Springer, Cham

3. Green WT, Wuts PG (2007) Protective groups in organic synthesis, 4th edn. Wiley, Hoboken

4. Kocienski PJ (2005) Protecting groups, 3rd edn. Thieme, New York

5. Young IS, Baran PS (2009) Nat Chem 1:193-205

6. Hickmann V, Kondoh A, Gabor B, Alcarazo M, Fürstner A (2011) J Am Chem Soc 133:13471-13480

7. Gonzalez-Sabin J, Morán-Ramallal R, Rebolledo F (2011) Chem Soc Rev 40:5321-5335

8. Bornscheuer UT, Kazlauskas RJ (1999) Hydrolases in organic synthesis. Wiley-VCH, Weinheim

9. Morimoto T, Murakami N, Nagatsu A, Sakakibara J (1994) Chem Pharm Bull 42:751-753

10. Iacazio G, Roberts SM (1993) J Chem Soc Perkin Trans $1: 1099-1101$

11. Alfonso I, Gotor V (2004) Chem Soc Rev 33:201-209

12. Parmar VS, Prasad AK, Sharma NK, Singh SK, Pati HN, Gupta S (1992) Tetrahedron 48:6495-6498

13. Nicolosi G, Piatelli M, Sanfilippo C (1993) Tetrahedron 49:3143-3148

14. Bayer S, Birkemeyer C, Ballschmiter M (2011) Appl Microbiol Biotechnol 89:91-98

15. Zheng RC, Yin XJ, Zheng YC (2016) J Chem Technol Biotechnol 91:1314-1319

16. Schober M, Faber K (2013) Trends Biotechnol 31:468-478

17. Roiban G-D, Sutton PW, Splain R, Morgan C, Fosberry A, Honicker K, Homes P, Boudet C, Dann A, Guo J, Brown KK, Ihnken LAF, Fuerst D (2017) Org Process Res Dev 21:1302-1310

18. Wang R, Hu D, Zong X, li J, Ding L, Wu M, Li J (2017) Biotechnol Lett 39:1917-1923

19. Sun Z, Lonsdale R, Wu L, Li G, Li A, Wang J, Zhou J, Reetz MT (2016) ACS Catal 6:1590-1597

20. Wu S, Chen Y, Xu Y, Li A, Xu Q, Glieder A, Li Z (2014) ACS Catal 4:409-420

21. Kotik M, Archelas A, Faměrová V, Oubrechtová P, Křen V (2011) J Biotechnol 156:1-10

22. Kotik M, Štěpánek V, Grulich M, Kyslík P, Archelas A (2010) J Mol Catal B 65:41-48

23. Xu Y, Jia X, Panke S, Li Z (2009) Chem Commun 12:1481-1483

24. Xu W, Xu J-H, Pan J, Gu Q, Wu X-Y (2006) Org Lett 8:1737-1740
25. Monterde MI, Lombard M, Archelas A, Cronin A, Arand M, Furstoss R (2004) Tetrahedron: Asymmetry 15:2801-2805

26. Steinreiber A, Mayer SF, Saf R, Faber K (2001) Tetrahedron: Asymmetry 12:1519-1528

27. Bellucci G, Chiappe C, Cordoni A (1996) Tetrahedron: Asymmetry 7:197-202

28. Kroutil W, Mischitz M, Plachota P, Faber K (1996) Tetrahedron Lett 37:8379-8382

29. Sadler JC, Humphreys LD, Snajdrova R, Burley GA (2017) ChemBioChem 18:992-995

30. Struck AW, Bennett MR, Shepherd SA, Law BJC, Zhuo Y, Wong LS, Micklefield J (2016) J Am Chem Soc 138:3038-3045

31. Law BJC, Bennett MR, Thompson ML, Levy C, Shepherd SA, Leys D, Micklefield J (2016) Angew Chem Int Ed 55:2683-2687

32. Siegrist J, Aschwanden S, Mordhorst S, Thöny-Meyer L, Richter M, Andexer JN (2015) ChemBioChem 16:2576-2579

33. Stecher H, Tengg M, Ueberbacher BJ, Remler P, Schwab H, Griengl H, Gruber-Khadjawi M (2009) Angew Chem Int Ed 48:9546-9548

34. Musa MM, Bsharat O, Karume I, Vielle C, Takahashi M, Hamdam SM (2018) Eur J Org Chem 2018:798-805

35. Médici R, Stammes H, Kwakernaak S, Otten LG, Hanefeld U (2017) Catal Sci Technol 7:1831-1837

36. Sarkar MR, Lee JHZ, Bell SG (2017) ChemBioChem 18:2119-2128

37. Rühlmann A, Antovic D, Müller TJJ, Urlacher VB (2017) Adv Synth Catal 359:984-994

38. Pennec A, Jacobs CL, Opperman DJ, Smit MS (2015) Adv Synth Catal 357:118-130

39. von Bühler CJ, Urlacher VB (2014) Chem Commun 50:4089-4091

40. Negretti S, Narayan ARH, Chiou KC, Kells PM, Stachowski JL, Hansen DA, Podust LM, Montgomery J, Sherman DH (2014) J Am Chem Soc 136:4901-4904

41. Bracco P, Janssen DB, Schallmey A (2013) Microb Cell Factor 12:95

42. Kille S, Zilly FE, Acevedo JP, Reetz MT (2011) Nat Chem 3:738-743

43. Bleif S, Hannemann F, Lisurek M, von Kries JP, Zapp J, Dietzen M, Antes I, Bernhardt R (2011) Chem Bio Chem 12:576-582

44. Furuya T, Kino K (2010) Appl Microbiol Biotechnol 85:1861-1868

45. Kühnel K, Maurer SC, Galeyeva Y, Frey W, Laschat S, Urlacher VB (2007) Adv Synth Catal 349:1451-1461

46. Paul CE, Rajagopalan A, Lavandera I, Gotor-Fernández V, Kroutil W, Gotor V (2012) Chem Commun 48:3303-3305

47. Nugent TC (2010) Chiral amine synthesis: Methods, developments and applications. Wiley-VCH, Weinheim

48. Höhne M, Bornscheuer UT (2009) ChemCatChem 1:42-51

49. Kroutil W, Fischereder EM, Fuchs CS, Lechner H, Mutti FG, Pressnitz D, Rajagopalan A, Sattler JH, Simon RC, Siirola E (2013) Org Process Res Dev 17:751-759

50. Ghislieri D, Turner NJ (2014) Top Catal 57:284-300

51. Kohls H, Steffen-Munsberg F, Höhne M (2014) Curr Opin Chem Biol 19:180-192

52. Patil MD, Grogan G, Bommarius A, Yun H (2018) Catalysts $8: 254-279$

53. Guo F, Berglund P (2017) Green Chem 19:333-360

54. Busto E, Simon RC, Richter N, Kroutil W (2016) In: Patel RN (ed) Green biocatalysis. Wiley, Hoboken, pp 17-57

55. Fuchs M, Farnberger JE, Kroutil W (2015) Eur J Org Chem 32:6965-6982

56. Mathew S, Yun H (2012) ACS Catal 2:993-1001

57. Savile CK, Janey JM, Mundorff EC, Moore JC, Tam S, Jarvis WR, Colbeck JC, Krebber A, Fleitz FJ, Brands J, Devine PN, Huisman GW, Hughes GJ (2010) Science 329:305-309 
58. Simon RC, Grischek B, Zepeck F, Steinreiber A, Belaj F, Kroutil W (2012) Angew Chem Int Ed 51:6713-6716

59. Simon RC, Zepeck F, Kroutil W (2013) Chem Eur J 19:2859-2865

60. Simon RC, Fuchs CS, Lechner H, Zepeck F, Kroutil W (2013) Eur J Org Chem 3397-3402

61. Payer SE, Schrittwieser JH, Grischek B, Simon RC, Kroutil W (2016) Adv Synth Catal 444-451

62. O'Reilly E, Iglesias C, Ghislieri D, Hopwood J, Galman JL, Lloyd RC, Turner NJ (2014) Angew Chem Int Ed 53:2447-2450

63. O'Reilly E, Turner NJ (2015) Perspect Sci 4:55-61

64. Mourelle-Insua A, Zampieri LA, Lavandera I, Gotor-Fernández V (2018) Adv Synth Catal 360:686-695

65. Koszelewski D, Clay D, Faber K, Kroutil W (2009) J Mol Catal B 60:191-194

66. Truppo MD, Rozzell JD, Turner NJ (2010) Org Process Res Dev 14:234-237

67. Hepworth LJ, France SP, Hussain S, Both P, Turner NJ, Flitsch SL (2017) ACS Catal 7:2920-2925

68. France SP, Hussain S, Hill AM, Hepworth LJ, Howard RM, Mulholland KR, Flitsch SL, Turner NJ (2016) ACS Catal 6:3753-3759

69. Schmidt NG, Eger E, Kroutil W (2016) ACS Catal 6:4286-4311

70. McCubbin JA, Maddess ML, Lautens M (2006) Org Lett 8:2993-2996

71. Song YL, Peach ML, Roller PP, Qiu S, Wang S, Long YQ (2006) J Med Chem 49:1585-1596

72. Jorgensen EC, Wiley RA (1963) J Pharm Sci 52:122-125

73. Yamada H, Kumagai H, Kashima N, Hiroshi Torii H (1972) Biochem Biophys Res Commun 46:370-374

74. Kumagai H, Yamada H, Matsui H, Ohkishi H, Ogata K (1970) J Biol Chem 245:1767-1772

75. Katayama T, Suzuki H, Koyanagi T, Kumagai H (2000) Appl Environ Microbiol 66:4764-4771

76. Foor F, Morin N, Bostian KA (1993) Appl Environ Microbiol 59:3070-3075
77. Kim S, Sung BH, Kim SC, Lee HS (2018) Chem Commun 54:3002-3005

78. Seisser B, Zinkl R, Gruber K, Kaufmann F, Hafner A, Kroutil W (2010) Adv Synth Catal 352:731-736

79. Ravikumar Y, Nadarajan SP, Yoo TH, Lee CS, Yun H (2015) J Biotechnol 10:1862-1876

80. Liu X, Li J, Hu C, Zhou Q, Zhang W, Hu M, Zhou J, Wang J (2013) Angew Chem Int Ed 52:4805-4809

81. Yu Y, Zhou Q, Wang L, Liu X, Zhang W, Hu M, Dong J, Li J, Lv X, Ouyang H, Li H, Gao F, Gong W, Lu Y, Wang J (2015) Chem Sci 6:3881-3885

82. Zhou Q, Hu M, Zhang W, Jiang L, Perrett S, Zhou J, Wang J (2013) Angew Chem Int Ed 52:1203-1207

83. Seyedsayamdost MR, Reece SY, Nocera DG, Stubbe J (2006) J Am Chem Soc 128:1569-1579

84. Yu Y, Lv X, Li J, Zhou Q, Cui C, Hosseinzadeh P, Mukherjee A, Nilges MJ, Wang J, Lu Y (2015) J Am Chem Soc 137:4594-4597

85. Dennig A, Busto E, Kroutil W, Faber K (2015) ACS Catal 5:7503-7506

86. Busto E, Gerstmann M, Tobola F, Dittmann E, Wiltschi B, Kroutil W (2016) Catal Sci Technol 6:8098-8103

87. Busto E, Simon RC, Kroutil W (2015) Angew Chem Int Ed 54:10899-10922

88. Yamaguchi M, Hayashi A, Hirama M (1995) J Am Chem Soc 117:1151-1152

89. Chen PY, Wu YH, Hsu MH, Wang TP, Wang EC (2013) Tetrahedron 69:653-657

90. Littke AF, Schwarz L, Fu GC (2002) J Am Chem Soc 124:6343-6348

91. Zhang H, Lu Y, Wu S, Wie Y, Liu Q, Liu J, Jiao Q (2016) J Mol Catal B 124:38-44

92. Busto E, Simon RC, Richter N, Kroutil W (2016) ACS Catal 6:2393-2397 